\title{
Diferenciales extremos de la mortalidad infantil en Honduras 2001
}

\author{
Nelson Raudales García \\ Ulda Borjas García \\ José F. Aguilar Sauceda \\ Claudio Borjas Garcia
}

\section{INTRODUCCIÓN}

Es de conocimiento general el interés que tiene el tema de la mortalidad infantil en la población. Es por ello la importancia de conocer el nivel de la mortalidad infantil y que variables de categorías extremas están relacionadas con las principal es causas de muerte en los niños.

Las principales causas de mortalidad infantil se producen por enfermedades prevenibles como las enfermedades respiratorias agudas (IRA S), diarreas y muertes relacionadas con el parto, además influyen las condiciones de las viviendas, el área de residencia, los niveles de escol aridad de la madre y el acceso a los servicios de salud.

El nivel de la mortalidad infantil es un reflejo de las condiciones económicas y sociales de los ciudadanos de un país así como de las políticas públicas en el área de servicios de salud y educación.

Como parte de este análisis se estudiaron las siguientes categorías extremas de las variables; relacionadas princi palmente con las condiciones de las viviendas, la zona de residencia y el nivel de escolaridad de las madres, con la intención de detectar diferenciales extremos de la mortalidad infantil. Los diferencial es de la misma ofrecen la oportunidad de entender cuales factores están asociados a la muerte 0 a la sobre vivencia de los niños.

Este estudio pretende aportar un análisis preliminar de la mortalidad infantil partiendo de condiciones extremas, tomando en cuenta las mejores y peores condiciones de las variables consideradas.

\section{Objetivo}

Realizar las estimaciones y el análisis de las tasas de mortalidad infantil según categorías de las variables extremas.

\section{METODOLOGÍA}

Las principales fuentes de información que se utilizan para el estudio de la mortalidad infantil son las estadísticas vitales, los censos nacionales y las encuestas de salud familiar

Lastimosamente en $\mathrm{H}$ onduras las estadísticas vitales son muy deficientes para estudiar por medio de ellas la mortalidad infantil, ya que presentan serios problemas de subregistro principalmente de las defunciones y los nacimientos.
Es por este motivo que es necesario recurrir a métodos indirectos de estimación de la mortalidad infantil, estos métodos se basan en información recopilada a través de preguntas específicas sobre el tema.

EI XVI C enso de Población y V de Vivien da 2001 fue la fuente principal de información para el estudio de la mortalidad infantil, desarrollando la técnica indirecta de William Brass con variantes Trusell, C oale y Demeny, utilizando como patrón el modelo oeste el cual supone que la mortalidad y fecundidad se han mantenido constantes en los últimos 10 años.

Esta metodología requiere como información básica: ${ }^{1}$

- Población femenina por grupos quinquenales de edad entre 15 y 49 años

- Número de hijos nacidos vivos, clasificados por grupos quinquenales de edad de las madres.

- $\quad$ Número de hijos supervivientes o fallecidos por grupos de edades quinquenales de la madre.

La técnica de Brass permite convertir las proporciones de hijos fallecidos en medidas más convencionales de la mortalidad, específicamente en probabilidades de morir entre el nacimiento y ciertas edades exactas, esto es posible si se considera que la proporción de hijosfallecidos de las mujeres de cierto grupo de edad depende de:

a) El tiempo durante el cual estos niños han estado expuestos al riesgo de morir.

b) Los riesgos de mortalidad.

En este apartado se analizaron las categorías extremas de variables como: Á rea de Residencia (urbano, rural); $N$ ivel Educativo de la M adre ( $N$ inguno, Secundaria y más); $C$ ondiciones de las Viviendas se consideraron aspectos relacionados con: Tipo de Piso de la

Cuadro No. 1. Honduras: mortalidad infantil según tipo de piso de las viviendas, 2001

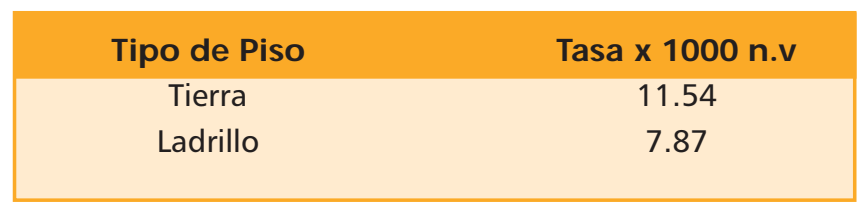

Fuente: Elaboración propia en base a Técnica de Brass, Variante Trusell, con datos de INE Censo de Población y Vivienda de Honduras, 2001

${ }^{*} \mathrm{n} . \mathrm{v}=$ nacido vivo 
vivienda (Tierra, Ladrillo); A bastecimiento de A gua ( $R$ ió o Vertiente, Tubería Publica o privada); Eliminación de Basura (Tira a la C alle, Lleva al Depósito.

Gráfico No. 1. Honduras tasa de mortalidad infantil según tipo de piso de las viviendas, 2001

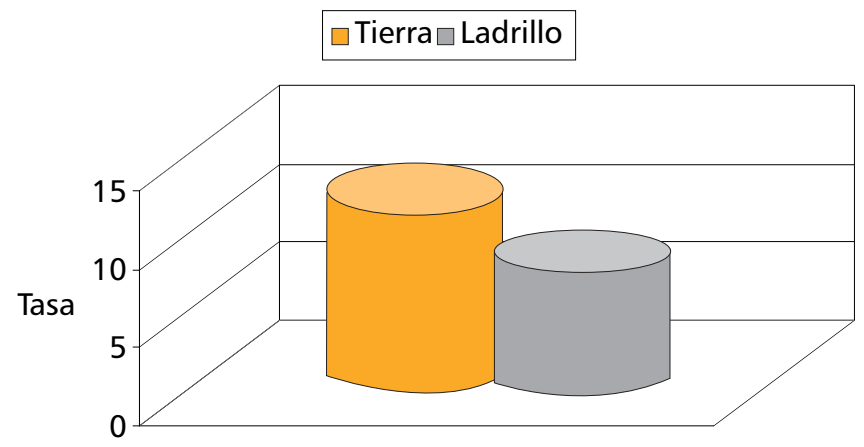

Funte: CEPAL, Boletín Demográfico No. 67, América Latina: Tablas de Mortalidad, 1950-2025. Chile, Enero de 2001

El tipo de piso de lasviviendas es un aspecto importante a considerar para el análisis de la mortalidad infantil ya que en las viviendascon piso de tierra la mortalidad es de 11.54 por mil nacidos vivos y las viviendas con tipo de piso de ladrillo la mortalidad es de 7.87 por cada mil nacidos vivos.

Este aspecto se relaciona con las enfermedades de las vías respiratorias como las infecciones respiratorias agudas (IRAS) y las enfermedades parasitarias dentro de las principales causas de muerte en los niños y esto son evidencia del estatus socioeconómico de las familias.

U n aspecto importante de mencionar es que al calcular la tasa de mortalidad infantil por tipo de piso en la vivienda, se refleja que la misma aparece con una tasa baja, no obstante resulta importante señalar que las categorías de la pregunta de tipo de piso de la vivienda son: Piso de tierra, plancha de cemento, madera, ladrillo de cemento, ladrillo de terrazo, ladrillo de barro, cerámica y otro.

Sin embargo, al generar una frecuencia de la variable en mención, se registra un total de 270,925 viviendas las que representan un $23 \%$ del total de las mismas, que no presentan ningún tipo de categorías mencionadas, esto debido a que en el momento de el cen-

\section{Cuadro No. 2 Honduras: mortalidad infantil según zona de residencia 2001}

\begin{tabular}{|cc|}
\hline Zona de Residencia & Tasa $\times 1000$ n.v \\
\hline Urbana & 27 \\
Rural & 39 \\
\hline
\end{tabular}

Fuente: Elaboración propia en base a Técnica de Brass, Variante Trusell, con datos de INE Censo de Población y Vivienda de Honduras, 2001 so, las viviendas estaban; ya sea en construcción o no existían ocupantes dentro de la misma, por lo que pueden estar subestimadas las tasas.

Gráfico No. 2. Honduras: tasa de mortalidad infantil según zona de residencia, 2001

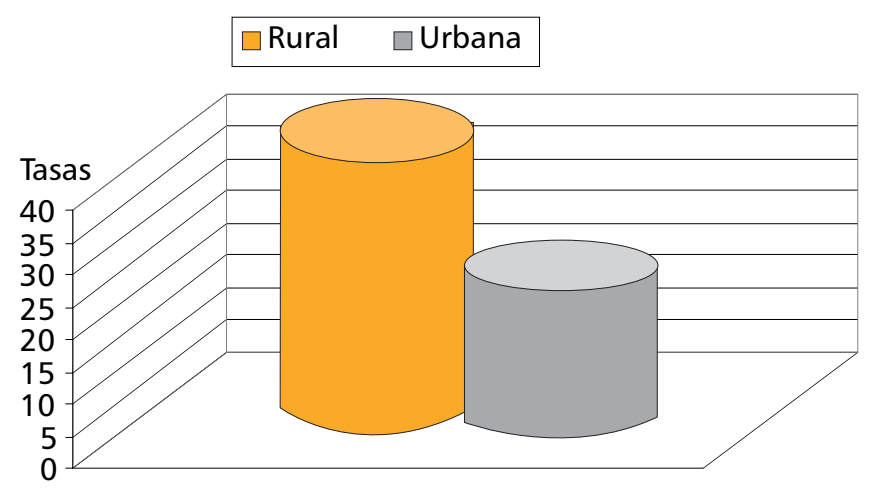

Funte: CEPAL, Boletín Demográfico No. 67, América Latina: Tablas de Mortalidad, 1950-2025. Chile, Enero de 2001

El comportamiento de la mortalidad infantil según zona de residencia es diferenciada y generalmente en el área rural las tasas son más altas que en el área urbana, debido a las condiciones socioeconómicas.

Por lo general en el área urbana existe mayor acceso a los servicios básicos, y a los servicios de salud. En el cuadro N o 2 observamos que en el área rural la Tasa de M ortalidad infantil es de 39 muertes por cada mil nacidos vivos mientras que para el área urbana es de 27 muertes por cada mil nacidos vivos.

El nivel educativo de la madre es un aspecto importante a considerar, ya que diversos estudios han demostrado que entre más al to es el nivel educativo de la madre, mejor es su disposición para al cuidado de sus hijos, a mejorar su higiene y su alimentación entre otros.

Los datos del cuadro N o. 3 nosmuestran quela tasa mortalidad infantil es mayor en las mujeres sin ningún nivel educativo, y en las mujeres con nivel secundaria diversificada la tasa disminuye significativamente.

Cuadro No 3 Honduras: mortalidad infantil según nivel educativo de la madre, 2001

\begin{tabular}{|cc|}
\hline NIvel Educativo & Tasa $\times 1000$ n.v \\
\hline Ninguno & 26.31 \\
Secundaria diversificada & 7.01 \\
\hline
\end{tabular}

Fuente: Elaboración propia en base a Técnica de Brass, Variante Trusell, con datos de INE Censo de Población y Vivienda de Honduras, 2001. 
Cuadro No 4. Honduras: mortalidad infantil según abastecimiento de agua en las viviendas, 2001

\begin{tabular}{|cc|}
\hline Procedencia del agua & Tasa $\times 1000$ n.v \\
\hline Río o Vertiente & 35.56 \\
Tubería & 20.5 \\
\hline
\end{tabular}

Fuente: Elaboración propia en base a Técnica de Brass, Variante Trusell, con datos de INE Censo de Población y Vivienda de Honduras, 2001.

Consideramos que el agua es un recurso vital para la vida de los seres human os y obtenerla en las mejores condiciones es fundamental, ya que el riesgo de contraer enfermedades relacionadas con la ingesta de agua contaminada puede provocar la muerte, especialmente en la niñez.

Según la información que nos presenta el cuadro No 4 observamos que en las viviendas que obtienen el agua de vertiente o río, la tasa de mortalidad infantil es mayor que en las viviendas donde el agua se obtiene de tubería pública o privada, debido a que el agua es potable, por lo cual está en mejores condiciones para el consumo humano y esto disminuye el riesgo de muerte en los niños.

\section{Gráfico No. 3. Tasa de mortalidad infantil según forma de eliminación de basura}

\section{$\square$ Tira a la Calle $\square$ Lleva al depósito}

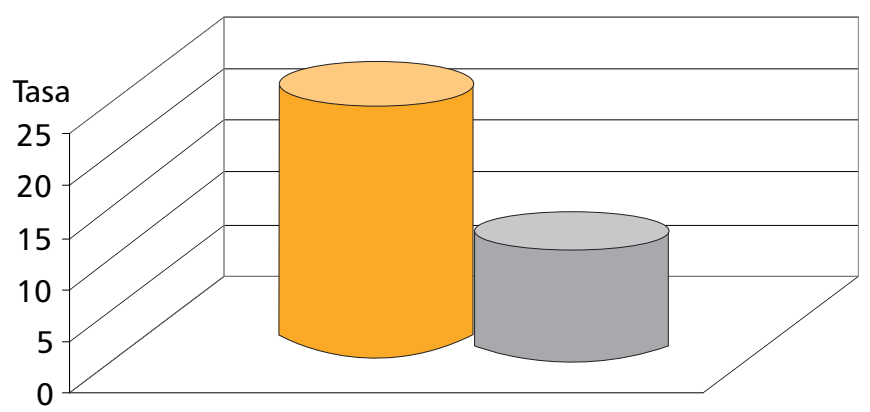

Funte: CEPAL, Boletín Demográfico No. 67, América Latina: Tablas de Mortalidad, 1950-2025. Chile, Enero de 2001
La intensidad de la contaminación del medio ambiente en el hogar está determinada por las interacciones de las características físicas de la vivienda, la higiene personal, las condiciones ambientales de la comunidad y la eliminación de la basura. ( $G$ arcía, M olina, 1996)

El problema de la eliminación de la basura en las viviendas es una seria dificultad según el gráfico N o. 3 la mayor parte de la población tira la basura a la calle, lo cual genera mayores tasas de mortalidad infantil, de igual forma esto se convierte en un foco de contaminación para los niños que por lo general son los más propensos a enfermarse de infecciones parasitarias, infecciones respiratorias, entre otras.

\section{Conclusiones}

1. Se puede notar claramente que a pesar de existir una mejoría en las condiciones de salud, todavía se siguen registrando altas tasas de mortalidad infantil por zonas de residencia. (U rbana, rural)

2. Las mayores tasas de mortalidad infantil se presentan en los grupos de mujeres donde la educación de las mismas es baja o que no presentan ningún nivel educativo en comparación con las mujeres del nivel educativo secundario diversificado.

3. La tasa de mortalidad infantil por categoría: tipo de piso, es mayor en las viviendas donde el piso es de tierra, que de ladriIlo; de igual forma cabe mencionar que dichas tasas son bajas debido a que hay una omisión de datos de las viviendas que representan el $23 \%$ aproximadamente, lo cual de cierto manera subestima la tasa en mención por dicha categoría.

4. Las mayores tasas de mortalidad infantil se presentan en viviendas con procedencia de agua de vertiente o río que de tubería pública, ello debido a que como es conocido la misma es insalubre para el consumo humano, de igual forma se detecta contaminación bacteriológica.

5. La tasa de mortalidad infantil por la eliminación de basura es mayor en las viviendas donde la tiran a la calle que en las viviendas donde la misma es depositada en los receptores de ésta, ya que como es sabido la basura que las personas tiran a la calle genera al tos grados de contaminación ambiental lo que a su vez crea consecuencias en la salud de las personas. 